\title{
Management of Chronic Obstructive Pulmonary
}

\section{Disease: A Personalized Interpretation of the Global} Initiative for Chronic Obstructive Lung Disease (GOLD) - ABCD Recommendations

Dave Singh, MD and Arjun Ravi, MBChB

The University of Manchester, Manchester Academic Health and Science Centre, NIHR Centre for Respiratory and Allergy, University Hospital of South Manchester Foundation Trust, Manchester, UK

\section{ABSTRACT}

The Global Initiative for Chronic Obstructive Lung Disease (GOLD) advocates a combined assessment of chronic obstructive pulmonary disease using lung function, symptoms, and exacerbation history to categorise patients into group A, B, C, or D. The aims of treatment are to reduce symptoms and prevent future risk, with the choice of treatment tailored according to the category. GOLD promotes an individualised approach to treatment. This review appraises the strengths and potential weaknesses of the current GOLD recommendations for combined assessment and pharmacological treatment of stable chronic obstructive pulmonary disease. There have been a number of recent publications applying the GOLD classification system to different chronic obstructive pulmonary disease populations. What can be learnt from these papers is reviewed, as well as the evidence base for the GOLD recommendations for pharmacological therapy. (BRN Rev. 2016;2:27-39) Corresponding author: Dave Singh, DSingh@meu.org.uk

Key words: COPD. Exacerbation. GOLD. Inhaled corticosteroids. Long-acting bronchodilator. 


\section{INTRODUCTION}

Chronic obstructive pulmonary disease (COPD) is a debilitating condition caused by cigarette smoking in the majority of cases. COPD is a leading cause of mortality worldwide ${ }^{1}$. The aims of the Global Initiative for Chronic $\mathrm{Ob}$ structive Lung Disease (GOLD) are to improve the diagnosis, management, and prevention of COPD ${ }^{2}$. The GOLD reports provide recommendations for clinicians based on a comprehensive review of current scientific evidence. This report is comprehensively rewritten at five-yearly intervals, with updates also provided annually ${ }^{2}$.

Based on recommendations in the GOLD 2001 and 2006 reports, clinicians historically have graded COPD severity using only the degree of airflow obstruction measured by the forced expiratory volume in one second $\left(\mathrm{FEV}_{1}\right)$. Patients have been classified with mild, moderate, severe, or very severe disease (GOLD stage 1, 2, 3 or 4, respectively) based on $\mathrm{FEV}_{1} \%$ predicted (Fig. 1). However, there is often a weak association between $\mathrm{FEV}_{1}$ and symptoms ${ }^{3}$. Furthermore, there has been increasing recognition of the importance of exacerbations, with the Evaluation of COPD Longitudinally to Identify Predictive Surrogate Endpoints (ECLIPSE) study defining a subgroup of patients who suffer from two or more exacerbations every year (frequent exacerbators $)^{4}$. The complexity and multidimensional nature of COPD led to the GOLD 2011 report advocating a combined assessment of disease severity that included symptoms, risk of future exacerbations, and the presence of comorbidities in addition to $\mathrm{FEV}_{1}$. These parameters are used to categorise patients into groups $\mathrm{A}, \mathrm{B}, \mathrm{C}$, or $\mathrm{D}$ as shown in figure 1 .
This combined assessment was closely aligned to the subsequent choice of pharmacotherapy, allowing an individual approach to treatment decisions, with the aim of pushing "COPD treatment towards individualized medicine - matching the patient's therapy more closely to his or her needs." GOLD 2011 states that the aims of COPD treatment are twofold: to relieve symptoms and to reduce the risk of future events such as exacerbations, decline in lung function, or death.

This article presents a personal view of the strengths and potential weaknesses of the current GOLD recommendations regarding the combined assessment (covered in GOLD chapter 2), and the closely related pharmacological treatment of stable COPD (covered in GOLD chapters 3 and 4). The combined assessment proposed in 2011 has stimulated a number of subsequent publications applying this classification system to COPD populations, both retrospectively and prospectively. These papers have generated further insights into the value of this system and stimulated thoughts on how to refine the system in future. All these aspects will be discussed.

\section{THE COMBINED ASSESSMENT EXPLAINED}

The modified Medical Research Council (mMRC) dyspnoea score $(\geq 2)^{5}$ or COPD Assessment Test (CAT) score $(\geq 10)^{6}$ are used to classify patients as having "low symptoms" (groups A or C) or "high symptoms" (groups $\mathrm{B}$ or D). An assessment of risk is performed based on exacerbation history and $\mathrm{FEV}_{1}$. An exacerbation is defined as an acute worsening of symptoms beyond the normal day-to-day 
A

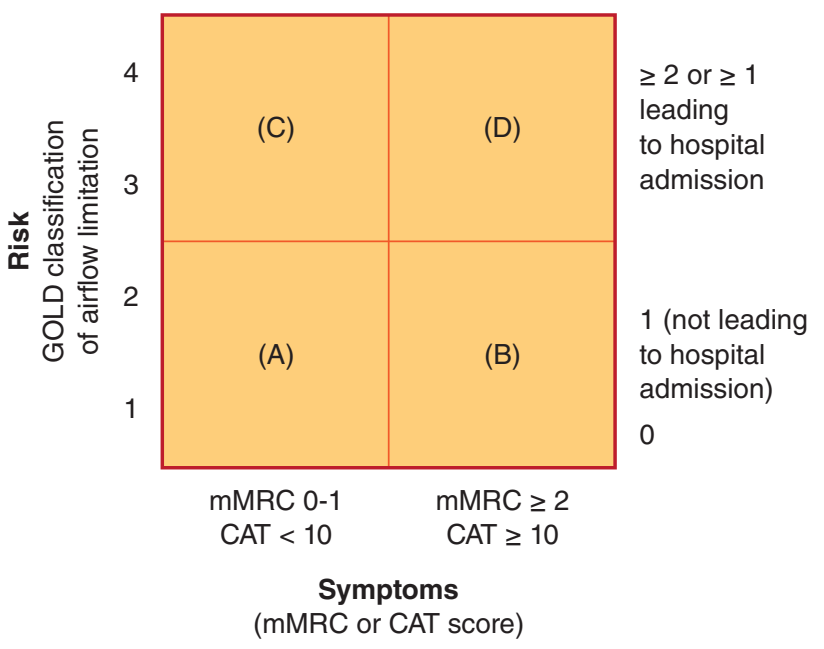

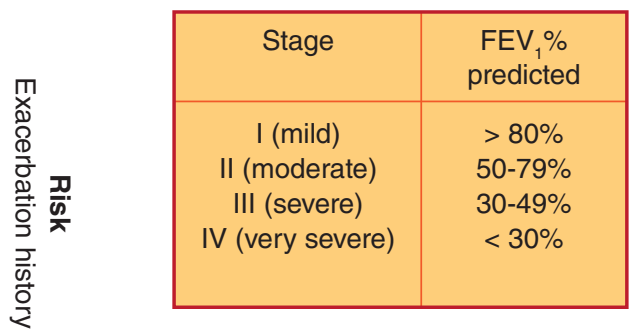

FIGURE 1. COPD assessment. (A) GOLD 2011 combined COPD assessment. (B) GOLD 2007 classification of airflow limitation. The GOLD 2011 (A) and GOLD 2006 (B) classifications for COPD. GOLD 2011 (A) classifies patients according to FEV $\%$ predicted, symptoms (assessed by mMRC or CAT) and exacerbation frequency/severity. GOLD 2006 (B) classified patients according to FEV $\%$ predicted only.

CAT: COPD assessment tool; FEV ; forced expiratory volume in one second; mMRC: modified Medical Research Council dyspnoea score.

variation? ${ }^{7}$ A history of previous exacerbations predicts the probability of future events ${ }^{4}$, and patients with frequent exacerbations have a worse prognosis ${ }^{8}$. GOLD defines a "frequent-exacerbator" on the basis of two exacerbations requiring oral corticosteroids and/or antibiotics or one hospitalisation in the last year. High-risk patients (groups $\mathrm{C}$ or D) have an $\mathrm{FEV}_{1}<50 \%$ predicted and/or a history of frequent exacerbations. An assessment for comorbidities should be made, but this does not influence the categorisation into group A, B, C, or D.

There may be a different risk categorisation attributed to exacerbation history and $\mathrm{FEV}_{1}$; in these individuals, it is recommended that the patient be categorised as high-risk. Patients may be classified as high-risk due to exacerbation history only, $\mathrm{FEV}_{1}$ only, or both factors; these three different subtypes of patient within GOLD C and D are illustrated in figure 2. This has caused some debate as the risk in these three groups is likely to differ. A further sub-classification of GOLD C and D into $\mathrm{C} 1, \mathrm{C} 2, \mathrm{C} 3$ and D1, D2, D3, depending on whether patients fulfil one or both criteria, has been proposed; ; this suggestion has been used in retrospective analysis ${ }^{10}$, but has not been adopted by GOLD.

Data from different COPD cohorts have been used to understand the percentage of patients falling into groups A, B, C, and D; these data are shown in table $1^{9,11-27}$. There are considerable differences between some studies, which can be attributed to many factors, including the study 


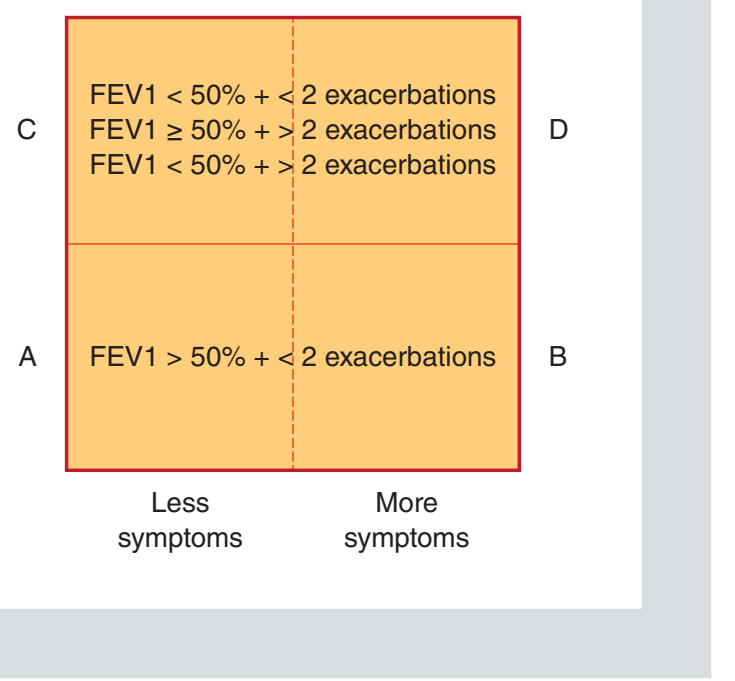

Figure 2. GOLD 2011 classification: $C$ and D groups are composed of three different types of patient. Note: patients can be high risk due to two exacerbations, or one hospitalisation. $\mathrm{FEV}_{1}$ : forced expiratory volume in one second.

design and inclusion criteria, how the patients were recruited (e.g. from hospital clinics or from the general population), and inherent differences between geographically distinct populations. For example, the publication by Lange et al. ${ }^{9}$ uses data from the Copenhagen City Heart Study and the Copenhagen General Population Study, both of which screened the general population using spirometry and so were able to detect new COPD cases at a relatively early stage of the disease; consequently, it is not surprising that this paper has a relatively large proportion of GOLD A patients.

Soriano et al. ${ }^{27}$ performed a pooled analysis of 15,632 patients from 22 cohorts, with data from some of these individual cohorts included in other studies, as shown in table 1 . The GOLD B and D patients comprised 19 and 31\%, respectively, which is generally consistent with other studies in table 1 that used mMRC to grade symptoms. GOLD C comprised 13\%, reflecting a general trend for this category to be a minority of the population. It should be noted that studies comparing the use of CAT and $\mathrm{mMRC}$ have generally shown an increase in severity towards more GOLD B and D patients using $\mathrm{CAT}^{11,16,20,21}$, indicating that these tools do not provide equivalent results.

\section{DOES COMBINED ASSESSMENT IMPROVE RISK STRATIFICATION?}

Some of the studies shown in table 1 have also provided data on mortality (Table 2). These mortality studies have consistently shown that group A has the lowest risk, while D has the highest risk. Some studies have shown that group $\mathrm{B}$ patients have worse risk compared to group $C^{9,12,15,22}$, giving a risk ordering of $A$ (lowest) $-C-B-D$ (highest), while for other studies the risk ordering is $\mathrm{A}-\mathrm{B}-\mathrm{C}-\mathrm{D}^{17-19,27}$; representative survival curves for these two patterns are shown in figure 3. There is evidence that groups $\mathrm{B}$ and $\mathrm{D}$ have the highest prevalence of patients with cardiovascular comorbidities ${ }^{14,15}$, which presumably contributes to the increased symptoms and also increased mortality risk. The assessment of comorbidities does not formally contribute to the classification of patients into A, B, C, or D, but it seems that COPD patients with cardiovascular comorbidities naturally fall into the higher symptom categories.

These studies have also shown that COPD classification based on $\mathrm{FEV}_{1}$ alone predicts mortality risk with a risk ordering GOLD 1 (lowest) $-2-3-4$ (highest); a representative survival curve is shown in figure 3 . This reinforces the value of $\mathrm{FEV}_{1}$ as a predictor of future risk. Furthermore, while GOLD ABCD 
TABLE 1. Distribution of COPD according to the GOLD 2011 Classification

\begin{tabular}{|c|c|c|c|c|c|c|}
\hline Study & Symptom assessment (mMRC/CAT) & Patients (n) & $A(\%)$ & B (\%) & $C(\%)$ & D (\%) \\
\hline \multirow[t]{2}{*}{ Jones et al. ${ }^{11} 2012^{\dagger}$} & mMRC & \multirow[t]{2}{*}{1,817} & 21 & 7 & 37 & 36 \\
\hline & CAT & & 8 & 19 & 9 & 63 \\
\hline Lange et al. ${ }^{9} 2012^{\#}$ & $\mathrm{mMRC}$ & 6,628 & 77 & 14 & 4 & 4 \\
\hline Agusti et al. ${ }^{12} 2013$ & mMRC & 2,101 & 24 & 14 & 23 & 40 \\
\hline Han et al. ${ }^{13} 2013^{\#}$ & mMRC & 4,484 & 20 & 25 & 5 & 41 \\
\hline Haughney et al. ${ }^{14} 2013$ & $\mathrm{mMRC}$ & 6,283 & 36 & 19 & 20 & 25 \\
\hline Johannessen et al. ${ }^{15} 2013^{\#}$ & mMRC & 912 & 21 & 29 & 6 & 43 \\
\hline \multirow[t]{2}{*}{ Kim et al. ${ }^{16} 2013^{\dagger}$} & mMRC & \multirow[t]{2}{*}{257} & 38 & 7 & 24 & 31 \\
\hline & CAT & & 23 & 21 & 8 & 47 \\
\hline Leivseth et al. ${ }^{17} 2013^{\#}$ & mMRC & 1,540 & 61 & 18 & 12 & 10 \\
\hline Nishimura et al. ${ }^{18} 2013$ & mMRC & 150 & 34 & 8 & 38 & 20 \\
\hline Soriano et al. ${ }^{19} 2013^{\#}$ & mMRC & 3,633 & 34 & 16 & 18 & 32 \\
\hline \multirow[t]{2}{*}{ Jones et al. ${ }^{20} 2014^{* \dagger}$} & mMRC & \multirow[t]{2}{*}{1,041} & 38 & 20 & 13 & 29 \\
\hline & CAT & & 9 & 49 & 1 & 42 \\
\hline \multirow[t]{2}{*}{ Price et al. ${ }^{21} 2014^{* \dagger}$} & mMRC & \multirow[t]{2}{*}{1,659} & 22 & 10 & 43 & 25 \\
\hline & CAT & & 5 & 27 & 7 & 61 \\
\hline de Torres et al. ${ }^{22} 2014$ & mMRC & 707 & 36 & 10 & 23 & 31 \\
\hline Frei et al..$^{23} 2014^{\#}$ & mMRC & 408 & 42 & 22 & 14 & 23 \\
\hline Vestbo et al. ${ }^{24} 2014^{*}$ & CAT & 3,813 & 10 & 49 & 1 & 40 \\
\hline Wesolowski et al. ${ }^{25} 2014$ & mMRC & 2,271 & 30 & 18 & 11 & 41 \\
\hline \multirow[t]{2}{*}{ Mapel et al. ${ }^{26} 2015^{\dagger}$} & mMRC & \multirow[t]{2}{*}{445} & 33 & 22 & 19 & 26 \\
\hline & CAT & & 9 & 45 & 4 & 42 \\
\hline Soriano et al. ${ }^{27} 2015^{\ddagger}$ & mMRC & 15,632 & 38 & 19 & 13 & 31 \\
\hline \multicolumn{7}{|c|}{$\begin{array}{l}\text { *Patients drawn from the Adelphi Respiratory Disease Specific Programme. } \\
\text { 'Studies in which both mMRC and CAT have been utilised to categorise COPD patients. } \\
\text { fPooled analysis from } 22 \text { COPD cohorts. } \\
\text { "Studies that were examined in Soriano et al. }{ }^{28} 2015 \text {. } \\
\text { CAT: COPD Assessment Test; mMRC: modified Medical Research Council Dyspnoea Scale. }\end{array}$} \\
\hline
\end{tabular}

is an important advance in the way we assess COPD, it appears to be no better than $\mathrm{FEV}_{1}$ alone for the prediction of future risk. Although both GOLD 2006 (using spirometry) and GOLD 2011 (using the combined assessment) classification systems predict mortality at a group level, neither system is sufficiently discriminatory for use at an individual level ${ }^{27}$.
The classification of patients into group A, B, C, or $\mathrm{D}$ at any point in time may change in the future. For example, in the ECLIPSE study 57, 36,47 , and $78 \%$ of patients in GOLD A, B, C, and $\mathrm{D}$, respectively, remained in the same category after three years ${ }^{12}$. A change of category may arise either through worsening or improvement of disease characteristics, which may 
TABLE 2. Mortality of COPD patients according to the GOLD 2011 Classification

\begin{tabular}{|l|c|c|}
\hline Study & Follow up (years) & $\begin{array}{c}\text { Risk of mortality according to GOLD 2011 classification } \\
\text { (lowest-highest) }\end{array}$ \\
\hline Lange et al. ${ }^{9} 2012^{*}$ & 9 & A, C, B, D \\
\hline Agusti et al. ${ }^{12} 2013$ & 3 & A, C, B, D \\
\hline Johannessen et al. ${ }^{15} 2013^{*}$ & 3 & A, C, B, D \\
\hline Leivseth et al. ${ }^{17} 2013^{*}$ & 15 & A, B, C, D \\
\hline Nishimura et al. ${ }^{18} 2013$ & 5 & A, B, C, D \\
\hline Soriano et al. ${ }^{19} 2013^{*}$ & 20 & A, B, C, D \\
\hline de Torres et al. ${ }^{22} 2014$ & 4 & A, C, B, D \\
\hline Soriano et al. ${ }^{27} 2015^{\dagger}$ & 70,184 & A, B, C, D \\
\hline $\begin{array}{l}\text { "Studies that were examined in Soriano et al. }{ }^{28} 2015 . \\
\text { tPerson years of follow-up. }\end{array}$ & & \\
\hline
\end{tabular}

be linked to changes in treatment. Clearly, the classification of patients using the current GOLD system is not static, and can be influenced by the level and type of healthcare provided.

\section{GOLD RECOMMENDATIONS FOR PHARMACOTHERAPY OF STABLE CHRONIC OBSTRUCTIVE PULMONARY DISEASE}

The classification of patients into group A, B, $\mathrm{C}$, or $\mathrm{D}$ is used to guide treatment decisions. While short-acting bronchodilators are used for symptom relief in all patients, and may be the only treatment prescribed in GOLD A patients, the choice of other pharmacological therapies varies according to the categorisation. Long-acting bronchodilators are used for GOLD A and B patients. For patients at greater risk of exacerbations (GOLD C and D), inhaled corticosteroid (ICS)/long-acting $\beta_{2}$-agonist (LABA) combination therapies are a firstchoice option, alongside long-acting muscarinic antagonist (LAMA) monotherapy, in order to prevent future exacerbations. The recent introduction of LABA/LAMA combinations provides another treatment option for GOLD B, C, and $\mathrm{D}$ patients; these drugs provide a greater effect on lung function than long-acting bronchodilator monotherapies ${ }^{28-37}$ and a benefit on symptoms, although the magnitude of effect observed in clinical trials has been smaller than the expected combined effect of the component monotherapies ${ }^{38}$. Roflumilast is a phosphodiesterase 4 inhibitor that reduces exacerbation rates in COPD patients with chronic bronchitis, $\mathrm{FEV}_{1}<50 \%$ predicted, and a history of exacerbations $^{39}$; consequently, this drug is recommended as a treatment option for appropriate GOLD C and D patients.

\section{Critical appraisal of GOLD recommendations for bronchodilator therapy}

GOLD 2011 was written at a time when the majority of evidence for using a LABA combined with a LAMA came from studies using 

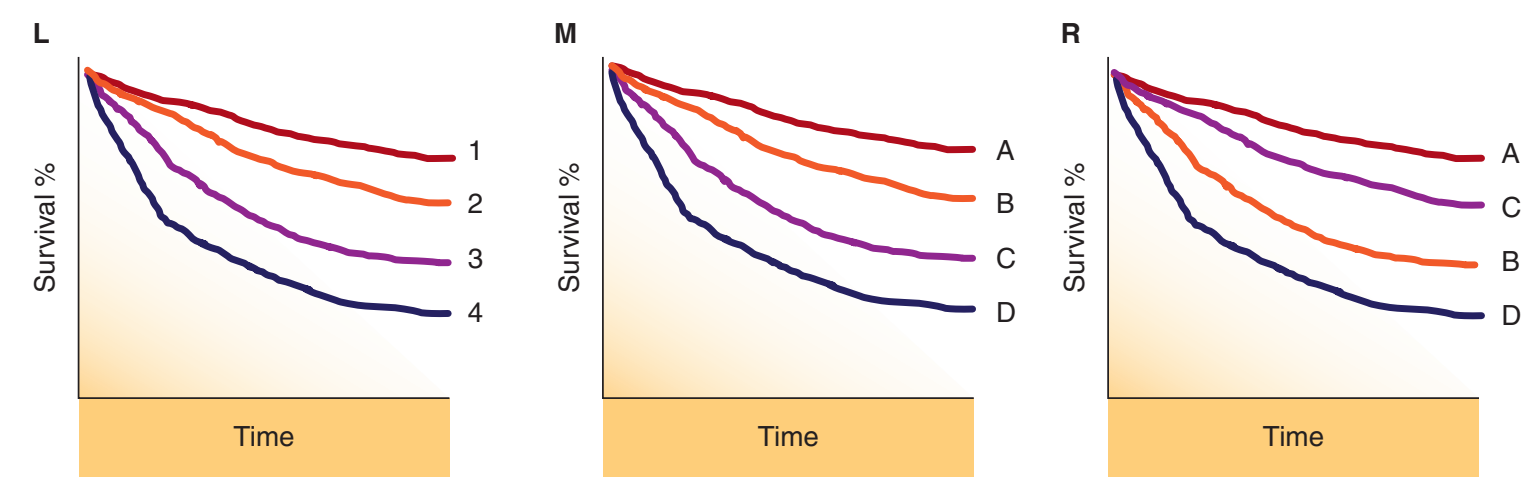

FIGURE 3. Representative survival curves for GOLD 1,2,3,4 (Left panel = L) and the two different patterns that can be observed with GOLD $A, B, C, D$ (Middle and Right panels $=\mathbf{M}$ and $\mathbf{R}$ respectively)

separate inhalers with varying sample sizes and study designs ${ }^{40,41}$. The development of LABA/LAMA combination inhalers has led to the publication of a number of well-powered clinical trial studies designed for regulatory purposes $^{28-37}$. These studies have generally been performed in patient populations with a low rate of exacerbations, and consequently the interpretation of the benefit on exacerbations compared to monotherapy is limited. However, one study performed in COPD patients with $\mathrm{FEV}_{1}$ $<50 \%$ predicted and a history of exacerbations showed significantly fewer exacerbations with indacaterol/glycopyrronium bromide compared to glycopyrronium bromide alone ( $12 \%$ reduction ${ }^{42}$. Although LABA/LAMA combinations are recommended for GOLD C and D, it would be desirable to have more evidence on exacerbations to support their use in patients who are frequent exacerbators.

Clinical trials using LABA/LAMA combination therapies have not included patients with $\mathrm{FEV}_{1}$ $>80 \%$, so the evidence for their benefit over long-acting bronchodilator monotherapies in milder COPD patients is lacking. In moderate-to-severe patients, there is consistent evidence of superiority for LABA/LAMA combinations over monotherapies in terms of lung function, but the evidence for improved symptoms, using the transition dyspnoea index (TDI), and health status, using the St Georges Respiratory Questionnaire (SGRQ), has been less consistent ${ }^{28-37}$. The thresholds used to define a minimal clinically important difference for TDI and SGRQ are a one-point increase and a four-point decrease, respectively ${ }^{43}$. Recent publications have shown that the difference between LABA/LAMA combinations and monotherapies is approximately 0.5 and 2.0 for TDI and SGRQ, respectively $28,29,33,34,44$. The traditional minimal clinically important difference (MCID) threshold values may not be applicable to studies comparing two active treatments, and the concept of the "minimal worthwhile incremental advantage" may be more useful in this context ${ }^{43}$. Alternatively, "responder analysis" can be used to understand the proportion of patients with treatment responses that reach the MCID threshold; 
generally, there are approximately 10-15\% greater responder rates with LABA/LAMA compared to monotherapy $28,31,34,35$. These improvements in patient-reported outcomes, coupled with reductions in reliever medication use, support the use of LABA/LAMA inhalers as a step up from long-acting bronchodilator monotherapy $^{38}$. However, clinical trials have not identified particular patient subgroups likely to gain the most benefit from LABA/LAMA combination treatments. It would be useful for the practising clinician to have some simple guidance to help predict the magnitude of symptom benefit likely to be achieved. The response to all pharmacological therapies (in all branches of medicine) is heterogeneous; clinical trials often report group mean data, but the heterogeneity of individual responses is important in clinical practice.

Do we have enough evidence to support the use of LABA/LAMA combination inhalers as first-line therapy, without first trying a long-acting bronchodilator monotherapy? No clinical trial has addressed this issue as a primary aim in COPD patients who have not previously used long-acting bronchodilators. However, evidence from primary care shows that the majority of COPD patients treated with a long-acting bronchodilator monotherapy remain significantly breathless ${ }^{45}$. It would be reasonable to infer that patients with more severe airflow obstruction and more symptoms are unlikely to be adequately treated with a long-acting bronchodilator monotherapy, and perhaps these patients would be good candidates to receive LABA/ LAMA monotherapy as first-line ${ }^{38}$.

The LABA/LAMA treatments have generally been studied in populations where patients with significant cardiovascular disease have been excluded. Although the safety profile of LABA/LAMA combination inhalers appears to be satisfactory, it would be desirable to have further information in higher cardiovascular risk populations. Considerations around the risk versus benefit of this new class of drug are important, as are cost considerations.

\section{Critical appraisal of GOLD recommendations for inhaled corticosteroids}

The ICS/LABA combination therapies are recommended for patients with higher risk (GOLD C and D). However, patients may be at higher risk because of exacerbation history, low $\mathrm{FEV}_{1}$, or both. The license for ICS/LABA combinations is for COPD patients with a history of exacerbations, based on the reduction in exacerbation rates observed in this subgroup $^{45-47}$. Current GOLD recommendations could be interpreted as not being exactly aligned to this evidence base, allowing ICS/LABA use in a wider population based on $\mathrm{FEV}_{1}$ as well as exacerbation history.

The ICS/LABA combination studies have predominantly enrolled patients with a history of one exacerbation in the last year ${ }^{10,48,49}$. The current GOLD definition of a frequent exacerbator is two exacerbations requiring oral corticosteroids and/or antibiotics or one hospitalisation. One could argue that the GOLD recommendation for ICS/LABA use does not match to the clinical trial evidence base. However, the counter argument is that a single exacerbation event in a year may be an isolated occurrence, as some of these patients can subsequently have no events in a year; two exacerbation events is a more likely predictor of future exacerbations ${ }^{4}$. 
Inhaled corticosteroids cause side effects including osteoporosis, diabetes, and cataracts ${ }^{48,50}$. Furthermore, there is a small but significantly increased rate of pneumonia in COPD patients treated with ICS ${ }^{45,48,49}$. These side effects make it important to prescribe ICS/LABA combinations only in GOLD C and D patients with a history of exacerbations, where the therapeutic index (benefits versus side effects) of these drugs is acceptable, as shown in randomised clinical trials. Post hoc analyses of two randomised clinical trials have shown that the blood eosinophil count at the start of the study predicts the subsequent degree of exacerbation reduction benefit for ICS/LABA compared to LABA in COPD patients with a history of one or more exacerbation ${ }^{51,52}$; the treatment difference for one of these studies is shown in figure 4. There is also evidence that corticosteroid effects are greater in COPD patients with raised sputum eosinophils ${ }^{53-56}$. Induced sputum cell counting is a technique that only specialised centres can perform, while blood eosinophil counts can be more easily measured. The precise mechanism for increased corticosteroid effect in more eosinophilic COPD patients is unclear; it may be that eosinophils are associated with a component of airway inflammation that is more corticosteroid sensitive. The use of blood eosinophils to predict treatment effects needs to be investigated in prospective studies before it can be used in clinical practice.

Clinical trials investigating the effects of ICS/ LABA combinations on exacerbations have often included patients with $\mathrm{FEV}_{1}<50 \%$ predicted and a history of exacerbations ${ }^{46,47}$. However, ICS/LABA combinations are also effective when including patients with a higher $\mathrm{FEV}_{1}$ threshold ${ }^{45,48}$; notably, it has recently

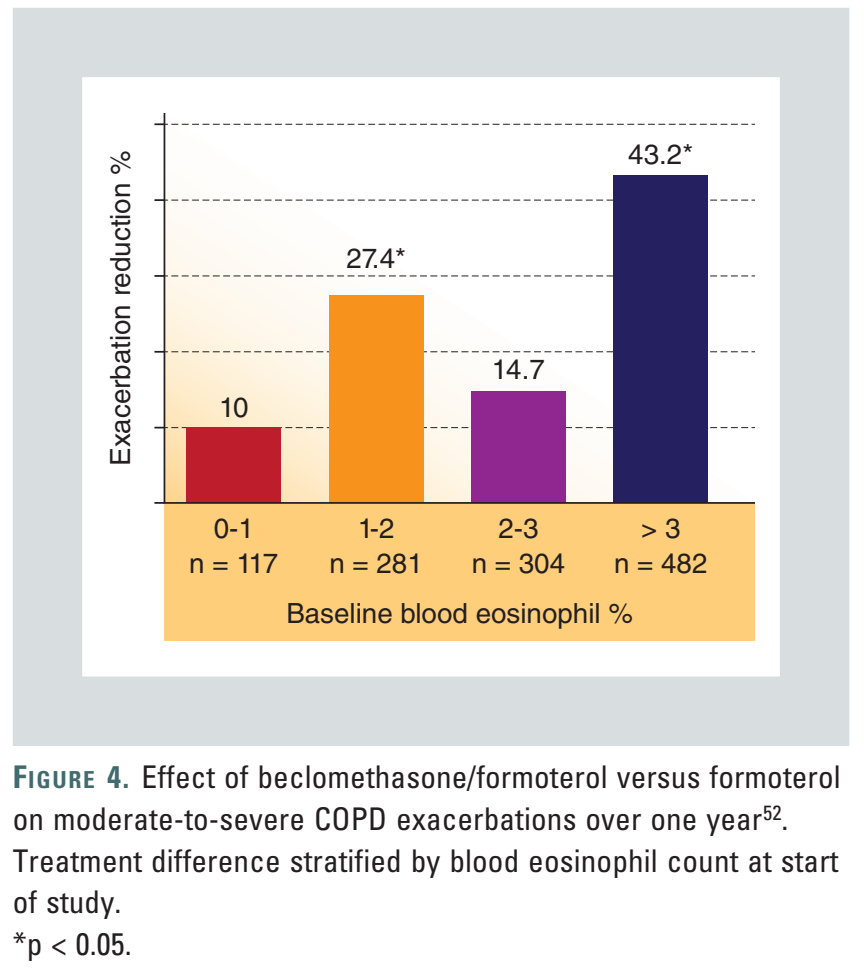

been shown that fluticasone furoate/vilanterol (ICS/LABA) had a greater effect on exacerbations than the LABA alone in patients with $\mathrm{FEV}_{1}<70 \%{ }^{45}$. These findings support the GOLD recommendation that exacerbation history alone, irrespective of $\mathrm{FEV}_{1}$, is a trigger to consider ICS/LABA treatment.

The Withdrawal of Inhaled Steroids during Optimized Bronchodilator Management (WISDOM) trial has provided further information on the benefits of ICS ${ }^{57}$. The COPD patients with $\mathrm{FEV}_{1}<50 \%$ predicted and a history of exacerbations were treated with "triple therapy" (ICS/LABA plus LAMA) during the run-in period, and then randomized into ICS withdrawal (continuing LABA and LAMA) or ICS maintenance (continuing triple therapy). The exacerbation rate was similar in the two groups after ICS withdrawal, while the withdrawal group showed a $40 \mathrm{ml}$ loss of $\mathrm{FEV}_{1}$ compared to triple 
therapy. The interpretation of the exacerbation rate is hindered by the low exacerbation rate in the study; approximately 0.5 exacerbations/patient/year. These data help us understand the benefit of ICS in severe COPD patients, despite the low exacerbation rate; ICS have a degree of benefit on lung function in patients treated with LABA and LAMA. Although the principal use of ICS (in the context of ICS/LABA combinations) is to reduce exacerbations, the WISDOM study (with ICS withdrawal) mirrors the effect of randomised controlled trials of ICS addition to LABA showing a lung function benefit ${ }^{46,47,49}$. It should be noted that only $39 \%$ of patients enrolled into the study were previously receiving triple therapy and only $70 \%$ were receiving ICS. The majority of the population were therefore "stepped-up" before randomisation to receive more inhaled therapy than they were previously receiving, as they did not require triple therapy in real life. This is a key point in the interpretation of this study as it probably contributes to the relatively low exacerbation rate observed.

\section{GOLD D; PHARMACOTHERAPY OPTIONS FOR THE MOST SEVERE CHRONIC OBSTRUCTIVE PULMONARY DISEASE PATIENTS}

The GOLD D patients have the highest level of both symptoms and risk. A common situation in clinical practice is that GOLD D patients have already been treated either with an ICS/LABA combination or a LAMA, but remain highly symptomatic and/or suffering with exacerbations. Such patients often are then stepped-up to receive triple therapy, which is a recommended first choice option for group D patients. Despite the common use of triple therapy in COPD, there are some gaps in our knowledge base for the effectiveness of this regime. Randomised clinical trials show that the addition of ICS/LABA to LAMA improves lung function, patient-reported outcomes, and exacerbation rates ${ }^{58-60}$. However, the evidence for the benefits of adding LAMA to ICS/LABA is not as comprehensive from clinical trials specifically designed to address this issue; lung function and patient-reported outcomes are improved ${ }^{61-63}$, but there has been no properly designed study to evaluate exacerbations. Similarly, the effect of adding ICS to LABA plus LAMA on exacerbations has not been demonstrated ${ }^{64}$. However, sub-analysis of the Foster 48-week Trial to Reduce Exacerbations in COPD (FORWARD) study showed that the exacerbation rate was reduced by addition of ICS in the subgroup of patients using LABA plus LAMA ${ }^{49}$. Prospective randomised clinical trials are on going, which will further inform us of the value of triple therapy compared to dual combinations (ICS/LABA or LABA/LAMA).

GOLD supports the use of roflumilast in combination with a long-acting bronchodilator or ICS/LABA combinations. The recently published Roflumilast in the Prevention of COPD Exacerbations While Taking Appropriate Combination Treatment (REACT) study now shows that this drug reduces exacerbation rates in patients treated with triple therapy ${ }^{39}$. Patients were required to have a history of two or more exacerbations in the last year in addition to $\mathrm{FEV}_{1}<50 \%$ and a history of chronic bronchitis. In terms of the exacerbation history, this is one of few examples of clinical trial design matching to the GOLD classification system. REACT supports the use of roflumilast as an add-on treatment in a 
situation often encountered in clinical practice: patients still suffering with exacerbations despite triple therapy.

There is evidence that macrolide antibiotics reduce exacerbation rates in COPD patients ${ }^{65,66}$. However, there are concerns regarding side effects, such as hearing loss and cardiovascular events, and potential problems with antibiotic resistance ${ }^{65}$. The benefits of mucolytics have been studied, with larger trials conducted in China showing an effect on exacerbations ${ }^{67,68}$. It is not clear whether clinical trial results from this geographical region predict a benefit of mucolytics in wider population groups. Nevertheless, given the paucity of therapeutic options available for GOLD D patients who are established on triple therapy but still suffer with exacerbations, the use of macrolides or mucolytics are a treatment option in these patients.

\section{TREATMENT PATHWAYS}

GOLD does not contain a pharmacological treatment algorithm showing a linear treatment pathway for clinicians. Linear algorithms are often found in treatment guidelines, and clinicians often find these easy to understand and follow. However, the wide variations in the availability of treatments between countries present some difficulties for GOLD to set out such an algorithm that could be used internationally. The intention of the GOLD report is that it should be used by different countries or respiratory societies to produce such pathways if desired.

Although $\mathrm{FEV}_{1}$ remains a marker of risk, there is growing debate on how useful it is for making treatment decisions ${ }^{69}$. Clinicians make treatment decisions to address symptoms and/or exacerbations, not the level of $\mathrm{FEV}_{1}$. The combined COPD assessment has promoted the routine assessment of symptoms and exacerbation history, leading to a more individualised approach to therapy, with bronchodilators being used to address symptoms and anti-inflammatory treatments used to address exacerbations. One could argue that the level of $\mathrm{FEV}_{1}$ is not a major influence on these decisions.

There has been much recent focus on the identification of COPD phenotypes, which are distinct subgroups of patients defined by clinical characteristics, prognosis, or response to therapy $^{70}$. The GOLD groups A, B, C, and D can be regarded as clinical phenotypes that require different treatments. An emerging concept is the definition of endotypes, which are patient subgroups defined by biological mechanisms ${ }^{71}$. Endotypes may cause one or more clinical characteristics, and multiple endotypes may be present in an individual patient. In the future, COPD therapy may move towards pharmacological targeting of endotypes, so that the treatment is closely matched to underlying biological mechanisms. Potential examples of COPD endotypes are patients with eosinophilic inflammation, patients with persistent bacterial colonisation, and subtypes of COPD exacerbations ${ }^{71}$. The development of biomarkers that identify endotypes will be important.

\section{CONCLUSIONS}

GOLD 2011 made a positive move to advance the way that we assess COPD, beyond just measuring $\mathrm{FEV}_{1}$. However, in terms of future risk stratification, this new model has not 
improved upon the simple measurement of $\mathrm{FEV}_{1}$ alone. Nevertheless, in terms of guiding pharmacological treatment, the new model offers a more individualised approach, with bronchodilator therapies targeted towards symptoms and anti-inflammatory drugs targeted towards exacerbations ${ }^{69}$. There are issues to be resolved, such as the confusion that may arise from patients being categorised as $\mathrm{C}$ or $\mathrm{D}$ on the basis of $\mathrm{FEV}_{1}$ or exacerbations or both, and how this relates to subsequent treatment choices. Further evidence is also needed to support and clarify debates regarding pharmacological treatment choices. While we deal with these issues, we hope that new therapies targeting novel mechanisms can be developed to treat COPD endotypes ${ }^{71}$.

\section{REFERENCES}

1. Mathers C, Loncar D. Projections of global mortality and burden of disease from 2002 to 2030. PLoS Med. 2006;3:e442.

2. Global Initiative for Chronic Obstructive Lung Disease (GOLD). Global strategy for the diagnosis, management and prevention of chronic obstructive pulmonary disease. 2014. Available at: www.goldcopd.org/guidelines-global-strategy-for-diagnosis-management.html

3. Nishimura M, Izumi T, Tsukino $M$ et al. Dyspnea is a better predictor of 5 -year survival than airway obstruction in patients with COPD. Chest. 2005;121:1434-40.

4. Hurst JR, Vestbo J, Anzueto A et al. Susceptibility to exacerbation in chronic obstructive pulmonary disease. N Engl J Med. 2010;363:1128-38.

5. Bestall JC, Paul EA, Garrod R, Garnham R, Jones PW, Wedzicha JA. Usefullness of the Medical Research Council (MRC) dyspnoea scale as a measure of disability in patients with chronic obstructive pulmonary disease. Thorax. 1999;54:581-6.

6. Jones PW, Harding G, Berry P, Wiklund I, Chen W-H, Kline Leidy N. Development and first validation of the COPD Assessment Test. Eur Respir J. 2009;34:648-54

7. Burge S, Wedzicha JA. COPD exacerbations: definitions and classifications. Eur Respir J. 2003;21:46-53s.

8. Soler-Cataluña JJ, Martinez García MA, Román Sánchez P, Salcedo E, Navarro M, Ochando R. Severe Acute Exacerbations and mortality in patients with chronic obstructive pulmonary disease. Thorax. 2005;60:925-31.

9. Lange P, Marott JL, Vestbo J et al. Prediction of the clinical course of chronic obstructive pulmonary disease, using the New GOLD classification - A study of the general population. Am J Respir Crit Care Med. 2012;186:975-81.

10. Anzueto A, Jenkins CR, Make BJ et al. Efficacy of an inhaled corticosteroid/ long acting $\beta 2$-agonist combination in symptomatic COPD patients in GOLD groups B and D. Eur Respir J. 2015;46:255-8.

11. Jones PW, Adamek L, Nadeau G, Banik N. Comparisons of health status scores with MRC grades in COPD: implications for the GOLD 2011 classification. Eur Respir J. 2012;42:647-54.
12. Agusti A, Edwards LD, Celli B et al. Characteristics, stability and outcomes of the 2011 GOLD COPD groups in the ECLIPSE cohort. Eur Respir J. 2013;42:636-46.

13. Han MK, Muellerova H, Curran-Everett D et al. Implications of the GOLD 2011 Disease Severity Classification in the COPDGene Cohort. Lancet Respir Med. 2013;1:43-50.

14. Haughney J, Gruffydd-Jones K, Roberts J, Lee AJ, Hardwell A, McGarvey L. The distribution of COPD in UK general practice using the new GOLD classification. Eur Respir J. 2014;43:993-1002.

15. Johannessen A, Nilsen RM, Storebø M, Gulsvik A, Eagan T, Bakke P. Comparison of 2011 and 2007 Global Initiative for Chronic Obstructive Lung Disease guidelines for predicting mortality and hospitalization. Am J Respir Crit Care Med. 2013;188:51-9.

16. Kim S, Oh J, Kim Y-I et al. Differences in classification of COPD group using COPD assessment test (CAT) or modified Medical Research Counci (mMRC) dyspnoea scores: a cross sectional analysis. BMC Pulm Med. 2013;13:35.

17. Leivseth L, Brumpton BM, Nilsen TIL, Mai X-M, Johnsen R, Langhammer A. GOLD classifications and mortality in chronic obstructive pulmonary disease: the HUNT Study, Norway. Thorax. 2013;68:914-21.

18. Nishimura M, Oga T, Tsukino M, Hajiro T, Ikeda A, Jones PW. Reanalysis of the Japanese experience using the combined COPD assessment of the 2011 GOLD classification. Respir Invest. 2013;52:129-35.

19. Soriano JB, Alfageme I, Almagro P et al. Distribution and prognostic validity of the new Global Initiative for Chronic Obstructive Lung Disease grading classification. Chest. 2013;143:694-702.

20. Jones PW, Nadeau G, Small M, Adamek L. Characteristics of a COPD population categorised using the GOLD framework by health status and exacerbations. Respir Med. 2014;108:129-35.

21. Price DB, Baker CL, Zou KH, Higgins VS, Bailey JT, Pike JS. Real-world characterization and differentiation of Global Initiative for Chronic Obstructive Lung Disease strategy classification. Int J COPD. 2014;9:551-61.

22. de Torres JP, Casanova C, Marín JM et al. Prognostic evaluation of COPD patients: GOLD 2011 versus BODE and the COPD comorbidity index COTE. Thorax. 2014;69:799-804.

23. Frei A, Muggensturm P, Putcha N et al. Five comorbidities reflected the health status in patients with chronic obstructive pulmonary disease: the newly developed COMCOLD index. J Clin Epidemiol. 2014;67:904-11.

24. Vestbo J, Vogelmeier C, Small M, Higgins VS. Understanding the GOLD 2011 Strategy as applied to a real world COPD population. Respir Med. 2014;108:729-36

25. Wesołowski S, Boros PW, Dębowski T. Chronic obstructive pulmonary disease in Poland: distribution of patients according to the new GOLD 2011 classification. Cross-sectional survey. Pneumonol Alergol Pol. 2014;82:511-17.

26. Mapel DW, Dalal AA, Johnson PT, Becker LK, Hunter AG. Application of the new GOLD COPD staging system to a US primary care cohort, with comparison to physician and patient impressions of severity. Int J COPD. 2015;10:1477-86

27. Soriano JB, Lamprecht B, Ramírez AS et al. Mortality prediction in chronic obstructive pulmonary disease comparing the GOLD 2007 and 2011 staging systems: a pooled analysis of individual patient data. Lancet Respir Med 2015;3:443-50.

28. Bateman ED, Ferguson GT, Barnes N et al. Dual bronchodilatation with QVA149 versus single bronchodilator therapy: the SHINE study. Eur Respir J. 2013;42:1484-94.

29. Mahler DA, Decramer M, D'Urzo A et al. Dual bronchodilation with QVA149 reduces patient-reported dyspnoea in COPD: BLAZE study. Eur Respir J. 2014;43:1599-609.

30. Mahler DA, Kerwin E, Ayers T et al. FLIGHT: Efficacy and safety of QVA149 (Indacaterol/Glycopyrrolate) versus its monocomponents and placebo in patients with COPD. Am J Respir Crit Care Med. 2015;192:1068-79.

31. Donohue JF, Maleki-Yazdi MR, Kilbride S, Mehta R, Kalberg C, Church A Efficacy and safety of once daily of once-daily umeclinidium/vilantero 62.5/25 mcg in COPD. Respir Med. 2013;107:1538-46. 
32. Decramer M, Anzueto A, Kerwin E et al. Efficacy and safety of umeclinidium plus vilanterol versus tiotropium, vilanterol or umeclinidium monotherapies over 24 weeks in patients with chronic obstructive pulmonary disease: results from two multicentre, blinded, randomised controlled trials. Lancet Respir Med. 2014;2:472-86.

33. Maleki-Yazdi MR, Kaelin T, Richard N, Zvarich M, Church A. Efficacy and safety of umeclinidium/vilanterol $62.6 / 25 \mathrm{mcg}$ and tiotropium $18 \mathrm{mcg}$ in chronic obstructive pulmonary disease: results of a 24-week, randomized, controlled trial. Respir Med. 2014;108:1752-60.

34. Singh D, Ferguson GT, Bolitschek J et al. Tiotropium + olodaterol shows clinically meaningful improvements in quality of life. Respir Med. 2015;109:1312-9.

35. Buhl R, Maltais F, Abrahams R et al. Tiotropium and olodaterol fixed dose combination versus mono-components in COPD (GOLD 2-4). Eur Respir J. 2015;45:969-79.

36. Singh D, Jones PW, Bateman ED et al. Efficacy and safety of aclidinium bromide/formoterol fumarate fixed-dose combinations compared with individual components and placebo in patients with COPD (ACLIFORM-COPD): a multicentre randomised study. BMC Pulm Med. 2014;14:178.

37. D'Urzo A, Rennard SI, Kerwin EM et al. Efficacy and safety of fixed-dose combinations of aclidinium bromide/formoterol fumarate: the 24-week, randomized, placebo-controlled AUGMENT COPD study. Respir Res. 2014;15:123.

38. Singh D. New combination bronchodilators for COPD: current evidence and future perspectives. Br J Clin Pharmacol. 2015;79:695-708.

39. Martinez FJ, Calverley PMA, Goehring U-M, Brose M, Fabbri LM, Rabe KF. Effect of roflumilast on exacerbations in patients with severe chronic obstructive pulmonary disease uncontrolled by combination therapy (REACT): a multicentre randomised controlled trial. Lancet. 2015;385:857-66.

40. Vogelmeier C, Kardos P, Harari S, Gans SJ, Stenglein S, Thirlwell J. Formoterol mono- and combination therapy with tiotropium in patients with COPD: a 6-month study. Respir Med. 2008;102:1511-20.

41. van Noord JA, Aumann JL, Janssens E et al. Combining tiotropium and salmeterol in COPD: Effects on airflow obstruction and symptoms. Respir Med. 2010;104:995-1004

42. Wedzicha JA, Decramer M, Ficker JH et al. Analysis of chronic obstructive pulmonary disease exacerbations with the dual bronchodilator QVA149 compared with glycopyrronium and tiotropium (SPARK): a randomised, double blind, parallel-group study. Lancet Respir Med. 2013;1:199-209.

43. Jones PW, Beeh KM, Chapman KR, Decramer M, Mahler DA, Wedzicha JA. Minimal clinically important differences in pharmacological trials. Am J Respir Crit Care Med. 2014;189:250-5.

44. Bateman E, Chapman KR, D’Urzo AD, Molins E, Leselbaum A, Gil EG. Aclinidium bromide and formoterol fumarate as a fixed-dose combination in COPD: pooled analysis of symptoms and exacerbations from two sixmonth, multicentre, randomised studies (ACLIFORM and AUGMENT). Respir Res. 2015;16:92.

45. Dransfield MT, Bourbeau J, Jones PW et al. Once-daily inhaled fluticasone furoate and vilanterol versus vilanterol only for prevention of exacerbations of COPD: two replicate double-blind, parallel-group, randomised controlled trials. Lancet Respir Med. 2013;1:210-23.

46. Szafranski W, Cukier A, Ramirez A et al. Efficacy and safety of budesonide/ formoterol in the management of chronic obstructive pulmonary disease. Eur Respir J. 2003;21:74-81.

47. Calverley PMA, Boonsawat W, Cseke Z, Zhong N, Olsson H. Maintenance therapy with budesonide and formoterol in chronic obstructive pulmonary disease. Eur Respir J. 2003;22:912-19.

48. Calverley PMA, Anderson JA, Celli BR et al. Salmeterol and fluticasone propionate and survival in chronic obstructive pulmonary disease. N Engl J Med. 2007;356:775-89.

49. Wedzicha JA, Singh D, Vestbo J et al. Extrafine beclomethasone/formoterol in severe COPD patients with history of exacerbations. Respir Med. 2014;108:1153-62.

50. Suissa S, Kezouh A, Ernst P. Inhaled corticosteroids and the risk of diabetes onset and progression. Am J Med. 2010;123:1001-6.
51. Pascoe S, Locantore N, Dransfield M, Barnes NC, Pavord ID. Blood eosiophil counts, exacerbations, and response to the addition of inhaled fluticasone furoate to vilanterol in patients with chronic obstructive pulmonary disease: a secondary analysis of data from two parallel randomised controlled trials. Lancet Respir Med. 2015;3:435-42.

52. Siddiqui SH, Guasconi A, Vestbo J et al. Blood eosinophils: A biomarker of response to extrafine beclomethasone/formoterol in chronic obstructive pulmonary disease. Am J Respir Crit Care Med. 2015;192:523-5.

53. Brightling CE, McKenna S, Hargadon B et al. Sputum eosinophilia and the short term response to inhaled mometasone in chronic obstructive pulmonary disease. Thorax. 2005;60:193-8.

54. Brightling CE, Montiero W, Ward R et al. Sputum eosinophilia and shortterm response to prednisolone in chronic obstructive pulmonary disease: randomised controlled trial. Lancet. 2000;356:1480-5.

55. Leigh R, Pizzichini MM, Morris MM, Maltais F, Hargreave FE, Pizzichini E. Stable COPD: predicting benefit from high-dose inhaled corticosteroid treatment. Eur Respir J. 2006;27:964-71.

56. Pizzichini E, Pizzichini MM, Gibson P et al. Sputum eosinophilia predicts benefit from prednisolone in smokers with chronic obstructive bronchitis. Am J Respir Crit Care Med. 1998;158:1511-17.

57. Magnussen H, Disse B, Rodriguez-Rosin R et al. Withdrawal of inhaled glucocorticoids and exacerbations of COPD. N Engl J Med. 2014;371:1285-94.

58. Welte T, Miravitlles M, Hernandez P et al. Efficacy and tolerability of budesonide/formoterol added to tiotropium in patients with chronic obstructive pulmonary disease. Am J Respir Crit Care Med. 2009;180:741-50.

59. Hanania NA, Crater GD, Morris AN, Emmett AH, O'Dell DM, Niewoehner DE. Benefits of adding fluticasone propionate/salmeterol to tiotropium in moderate to severe COPD. Respir Med. 2012;106:91-101.

60. Jung KS, Park HY, Park SY et al. Comparison of tiotropium plus fluticasone propionate/salmeterol with tiotropium in COPD: a randomized controlled study. Respir Med. 2012;106:382-9.

61. Singh SD, Brooks J, Hagan G, Cahn A, O'Connor B. 'Triple' therapy with salmeterol/fluticasone propionate and tiotropium bromide versus individual components in moderate to severe COPD. Thorax. 2008;63:592-8.

62. Frith PA, Thompson PJ, Ratnavadivel R et al. Glycopyrronium once-daily significantly improves lung function and health status when combined with salmeterol/fluticasone in patients with COPD: the GLISTEN study, a randomised control trial. Thorax. 2015;70:519-27.

63. Siler TM, Kerwin E, Sousa AR, Donald A, Ali R, Church A. Efficacy and safety of umeclidinium added to fluticasone furoate/vilanterol in chronic obstructive pulmonary disease: Results of two randomised studies. Respir Med. 2015;109:1155-63.

64. Aaron SD, Vandemheen KL, Fergusson D et al. Tiotropium in combination with placebo, salmeterol, or fluticasone-salmeterol for treatment of chronic obstructive pulmonary disease. Ann Intern Med. 2007;146:545-55.

65. Albert RK, Connett JE, Bailey WC et al. Azithromycin for prevention of exacerbations of COPD. N Engl J Med. 2011;365:689-98.

66. Uzun S, Djamin RS, Kluytmans JA et al. Azithromycin maintenance treatment in patients with frequent exacerbations of chronic obstructive pulmonary disease (COLUMBUS): a randomised, double-blind, placebo controlled trial. Lancet Respir Med. 2014;2:361-8.

67. Tse HN, Raiteri L, Wong KY et al. High-dose N-acetylcysteine in stable COPD; the 1-year double blind, randomized, placebo controlled HIACE study. Chest. 2013;144:106-8.

68. Zheng JP, Wen FQ, Bai CX et al. Twice daily N-acetylcysteine $600 \mathrm{mg}$ for exacerbations of chronic obstructive pulmonary disease (PANTHEON): a randomised, double-blind placebo-controlled trial. Lancet Respir Med. 2014;2:187-94.

69. Agusti A, Fabbri LM. Inhaled steroids in COPD: when should they be used? Lancet Respir Med. 2014;2:869-71.

70. Han MK, Agusti A, Calverley PMA et al. Chronic obstructive pulmonary disease phenotypes: the future of COPD. Am J Respir Crit Care Med. 2010;182:598-604.

71. Woodruff PG, Agusti A, Roche N, Singh D, Martinez FJ. Current concepts in targeting chronic obstructive pulmonary disease pharmacotherapy: making progress towards personalized management. Lancet. 2015;385:1789-98. 